OPEN ACCESS

Edited by: Aldo Eugenio Calogero, University of Catania, Italy

Reviewed by: Settimio D'Andrea, University of L'Aquila, Italy Winnie Shum,

ShanghaiTech University, China

*Correspondence:

Carlo Foresta

carlo.foresta@unipd.it

Specialty section:

This article was submitted to Reproduction,

a section of the journal

Frontiers in Endocrinology

Received: 26 November 2020

Accepted: 19 January 2021

Published: 09 March 2021

Citation:

Franzago M, Sabovic I, Franchi S, De Santo M, Di Nisio A, Luddi A, Piomboni $P$, Vitacolonna E, Stuppia $L$ and Foresta C (2021) Sperm DNA Methylation at Metabolism-Related Genes in Vegan Subjects.

Front. Endocrinol. 12:633943. doi: 10.3389/fendo.2021.633943

\section{Sperm DNA Methylation at Metabolism-Related Genes in Vegan Subjects}

\author{
Marica Franzago ${ }^{1,2}$, Iva Sabovic ${ }^{3,4}$, Sara Franchi ${ }^{2,5}$, Maria De Santo ${ }^{6}$, Andrea Di Nisio ${ }^{3}$, \\ Alice Luddi ${ }^{7}$, Paola Piomboni ${ }^{7}$, Ester Vitacolonna ${ }^{1,2}$, Liborio Stuppia ${ }^{2,5}$ \\ and Carlo Foresta ${ }^{3 *}$ \\ 1 Department of Medicine and Aging, School of Medicine and Health Sciences, "G. D'Annunzio" University, Chieti-Pescara, \\ Chieti, Italy, ${ }^{2}$ Center for Advanced Studies and Technology (CAST), "G. D'Annunzio" University, Chieti-Pescara, Chieti, Italy, \\ ${ }^{3}$ Unit of Andrology and Reproductive Medicine, Department of Medicine, University of Padova, Padova, Italy, ${ }^{4}$ Department of \\ Clinical and Experimental Sciences, University of Brescia, Brescia, Italy, ${ }^{5}$ Department of Psychological, Health and Territorial \\ Sciences, School of Medicine and Health Sciences, "G. D'Annunzio" University, Chieti-Pescara, Chieti, Italy, ${ }^{6}$ Casa di Cura \\ Privata Spatocco, Chieti, Italy, ${ }^{7}$ Department of Molecular and Developmental Medicine, University of Siena, Siena, Italy
}

Objective: To investigate if epigenome of sperm cells could be dynamically affected by nutrition.

Design and Methods: We assessed 40 healthy volunteers with different dietary habits and collected their demographic characteristics, as well as clinical and anthropometric parameters. We compared methylation profiles in sperm quantified by bisulfite pyrosequencing, at promoter-associated CpG sites of genes involved in metabolism including fat mass and obesity-associated (FTO) and melanocortin-4 receptor (MC4R) from six vegans and 34 omnivores. In addition, the FTO rs9939609 (T>A) was genotyped.

Results: Higher DNA methylation levels were detected in the sperm of vegan at $F T O$ gene CpG1 ( $p=0.02), C p G 2(p=0.001), C p G 3(p=0.004)$, and CpG4 $(p=0.003)$ sites and at MC4R-CpG2 site $[p=0.016]$ as compared to sperm of omnivores. This association was not related to FTO genotype.

Conclusions: Although limited by the small number of investigated cases, our data provide insight into the role of diet on sperm DNA methylation in genes involved in metabolism.

Keywords: sperm, vegan, epigenetic, reproduction, nutrition

\section{INTRODUCTION}

Epigenetic modifications, including DNA methylation, histone marks and small non-coding RNAs, are stable and mitotically heritable changes that modulate normal and disease-related phenotypic differences. Among environmental factors able to induce epigenetic modifications, a key role is played by diet. Dietary habits can result in epigenetic modifications by acting directly on metabolism genes to up- or downregulate pathways involved in the bioavailability of nutrients (1). In addition, it has been also suggested that nutrition induced epigenetic modifications of gene expression can influence metabolism and susceptibility to non-communicable diseases (NCDs) (2-4). 
To date, growing evidence suggests that the sperm epigenome can be dynamically affected by lifestyle (nutrient supply, physical exercise, alcohol and tobacco consumption) influencing not only male individual health status, but also his reproductive fitness and even the future offspring's health (5-9). Several studies have demonstrated that the spermatozoa from obese humans as well as from rats exposed to different models of diet, such as high-fat or low-protein diet, show an altered epigenetic signature, raising the question of a possible epigenetic inheritance of metabolic dysfunction $(8,10)$. Therefore, the possible role of diet in improving the quality of human sperm is becoming widely explored in the context of male infertility focusing on sperm epigenetic modifications (11).

Unlike omnivore diet, defined as a diet consuming all types of foods, the vegan diet is characterized by total exclusion of any animal derived substance, being thus very rich in fibres, but poor in proteins and fats (12). To date, this kind of diet is increasingly widespread in western societies, but its prevalence remains low (13). Although few studies described vegan diet as healthy, no conclusive data have been obtained yet (14-16), and vegan diet often requires supplementation of additional nutrients, at least during pregnancy (17).

To the best of our knowledge, the association between vegan diet and sperm DNA methylation patterns in human has not been investigated yet. In order to fill this gap, therefore, in the present study we investigated the effects of vegan diet as compared to omnivore diet on DNA methylation profiles in sperm at promoter-associated $\mathrm{CpG}$ sites of genes involved in metabolism, namely fat mass and obesity-associated (FTO) and melanocortin-4 receptor (MC4R).

FTO gene encodes for an AlkB-like 2-oxoglutarate-dependent nucleic acid demethylase, a potential regulator of RNA modification. It is highly expressed in the hypothalamus, visceral fat and liver but its function remains undefined. Recent studies reported that FTO seems to influence the Iroquois homeobox 3 (IRX3) expression with effects on body weight (18).

MC4R protein is a membrane-bound G-protein-coupled receptor found in brain regions, including the paraventricular nucleus in the hypothalamus (19) and common genetic variations near MC4R are involved in food intake by participating in appetite control and energy balance regulation (20-26).

Polymorphisms in these genes have been associated with body weight and composition, obesity, Type 2 Diabetes Mellitus (T2DM) and eating behavior (27-37).

The aim of this study is to evaluate the effect of vegan diet on sperm DNA methylation as a model to understanding the epigenetic effect of nutrition on male gametes and provide information for possible diet-based therapeutic strategies for improve male reproductive fitness.

\section{MATERIALS AND METHODS}

\section{Study Participants}

This is a multicentric study involving the Unit of Andrology and Reproductive Medicine of the Department of Medicine of the University of Padua (Italy), the Laboratory of Molecular
Genetics, School of Medicine and Health Sciences, "G. D’Annunzio" University of Chieti (Italy), the Center for Diagnosis and Cure of Couple infertility, University of Siena (Italy) and the Spatocco Clinic, Chieti (Italy). Forty healthy subjects with different dietary habits were recruited. In particular, six cases have been following a vegan diet for at least 2 years, and the remaining 34 an omnivore diet. Exclusion criteria were obstructive azoospermia and known causes of infertility (previous or concomitant testicular cancer, orchitis, testicular torsion and trauma, use of gonadotoxic drugs, oncological diseases, karyotype anomalies, Y chromosome long arm microdeletions, mutations in the androgen receptor and varicocele).

The study of sperm DNA methylation was conducted at the Laboratory of Molecular Genetics, School of Medicine and Health Sciences, “G. D’Annunzio” University of Chieti, Italy.

\section{Patients}

During the visit, data on demographic characteristics, anthropometric, and clinical parameters were collected. In addition, smoking habits and supplement intake were reported. Finally, physical activity (PA) was assessed registering the different levels of intensity (low, moderate, and high PA). All subjects underwent semen donation by masturbation into sterile containers after 2-5 days of sexual abstinence. Samples were allowed to liquefy for $30 \mathrm{~min}$ and were examined for sperm count, viability, motility and morphology according to the WHO criteria (38).

Sperm were isolated by using Percoll gradient centrifugation. After decondensation with proteinase $\mathrm{K}$ for total of $4 \mathrm{~h}$ DNA was extracted using the QIAamp ${ }^{\circledR}$ DNA Mini Kit according to manufacturer's recommendations.

The study was approved by the Ethics Committee of the University of Padua, Italy (protocol number \#2208). In accordance with the Declaration of Helsinki, all participants gave their written informed consent prior to their inclusion in the study.

\section{DNA Methylation Analysis}

The promoter associated CpG sites were tested in FTO gene (16q12.2, 4 CpGs sites), MC4R gene (18q21.32, 2 CpGs sites) and the imprinted gene $H 19$ (11p15.5, 5 CpGs sites). FTO and MC4R genes were selected due to their correlation with obesity, metabolism and appetite control. H19 gene was included as a control, being maternally expressed only and thus expected to show a full methylation in male gametes. After bisulfite treatment, DNA ( 20 ng) was amplified by PCR using the Kapa Hifi Hotstart Uracil+ HotStart Ready mix (Roche Diagnostics), according to manufacturer's recommendations.

Once NaBis-DNA amplified, the pyrosequencing was carried out using the PyroMark Q96 MD pyrosequencing instrument (Qiagen) with PCR and sequencing primers for the region of interest in the FTO and MC4R genes selected according to previous studies (39). In addition, PCR and sequencing primers for analysis of the H19 CpGs were designed with PyroMark Assay Design (version 2.0.1.15; Qiagen). Primers information for these genes can be found in Table $\mathbf{1}$. 
TABLE 1 | Primers for bisulfite PCR and pyrosequencing.

\begin{tabular}{|c|c|c|c|}
\hline Gene & Primers & $\begin{array}{l}\text { Product size } \\
(\mathrm{pb})\end{array}$ & $\begin{array}{l}\text { Number of CpGs } \\
\text { analyzed }\end{array}$ \\
\hline FTO & $\begin{array}{l}\text { F: TITGGAGTTATIIIIIITTGAGTAGAAAR: [Btn]ATTCTCCTTAAACTCTAACCTATTTACTS: } \\
\text { TITAGGTTAGATAGTTGGAAGA }\end{array}$ & 168 & 4 \\
\hline MC4R & $\begin{array}{l}\text { F: AGGGTGATATAGATTIAGATGTAGAAGTR: [Btn]AAACAATATACTTCCATTTCATTTACACS: } \\
\text { GTAGAAGTITTGAAGTTG }\end{array}$ & 220 & 2 \\
\hline$H 19$ & F: GGTाTGGAGGTTAGTGTाTR: [Btn]CTCAACCCCTAAAACTAACTTAACAS: TTGTATTATाIIIIITाGAGAGT & 322 & 5 \\
\hline
\end{tabular}

\section{Genotyping}

The rs9939609 (T>A) SNP in FTO was genotyped in twenty-five subjects by PCR amplification $\left(95^{\circ} \mathrm{C}\right.$ for $10 \mathrm{~min}$, followed by 35 cycles of $95^{\circ} \mathrm{C}$ for $30 \mathrm{~s}, 60^{\circ} \mathrm{C}$ for $30 \mathrm{~s}, 72^{\circ} \mathrm{C}$ for $30 \mathrm{~s}$ and a final extension at $72^{\circ} \mathrm{C}$ for $10 \mathrm{~min}$ ) and direct sequencing procedure using BigDye Term v3.1 CycleSeq Kit (Life Technologies, Monza, Italy) followed by automatic sequencing analysis.

\section{Statistical Analysis}

The subjects were stratified according to dietary habits and differences between the two groups were tested by the MannWhitney $\mathrm{U}$ for continuous variables or the Chi-square test for categorical variables. Shapiro-Wilk test showed a non-normal distribution of methylation levels. Thus, non-parametric analysis was conducted.

Moreover, to test the effect of genotypes on body mass index (BMI) as well as the effect of genotypes on methylation levels, a Nonparametric Kruskal-Wallis test was performed.

The quantitative variables were summarized as means and standard deviation (SD). Qualitative variables were summarized as percentage. All tests were 2-sided, and a level of statistical significance was set at $\mathrm{p}<0.05$. All analyses were performed with SPSS version 20 .

\section{RESULTS}

The demographic and clinical characteristics of study participants are summarised in Table 2 . No difference was present in mean age and in BMI between vegan and omnivorous men.

The vegans reported no assumption of any type of dietary supplement. In addition, no significant difference was reported in physical activity and smoking between the subjects in the two groups. Sperm count parameters showed no significant difference in the two groups. All subjects had a normal sperm count, except one subject in the omnivore group and one in the vegan group who had mild oligozoospermia ( $<15$ million/ml) and severe oligozoospermia $(<5 \mathrm{million} / \mathrm{ml})$, respectively.

Methylation profiles of sperm DNA from all men recruited are reported in Table 3. Vegan subjects showed higher sperm DNA methylation levels as compared to omnivorous men at FTO gene CpG1 ( $\mathrm{p}=0.02)$, CpG2 $(\mathrm{p}=0.001)$, CpG3 ( $\mathrm{p}=0.004)$, and CpG4 $(\mathrm{p}=0.003)$ sites. In addition, the mean DNA methylation percentages for the overall CpGs at FTO gene in sperm of vegan men were higher than in sperm of omnivorous men $(\mathrm{p}=0.001)$.

DNA methylation levels at MC4R-CpG1 site were not significantly different between vegan and omnivorous men, whereas DNA methylation levels at MC4R-CpG2 site were significantly different between the two groups $(\mathrm{p}=0.016)$. On the other hand, all the analyzed CpG sites of the H19 gene were close to $100 \%$ of methylation in all the samples, consistently with their maternal imprinting. However, DNA methylation levels at H19 gene CpG sites were slightly lower in sperm DNA of omnivores than in vegan men, although only CpG3 value did reach significance $(\mathrm{p}=0.007)$.

TABLE 2 | Demographic and clinical characteristics of healthy vegans and omnivore.

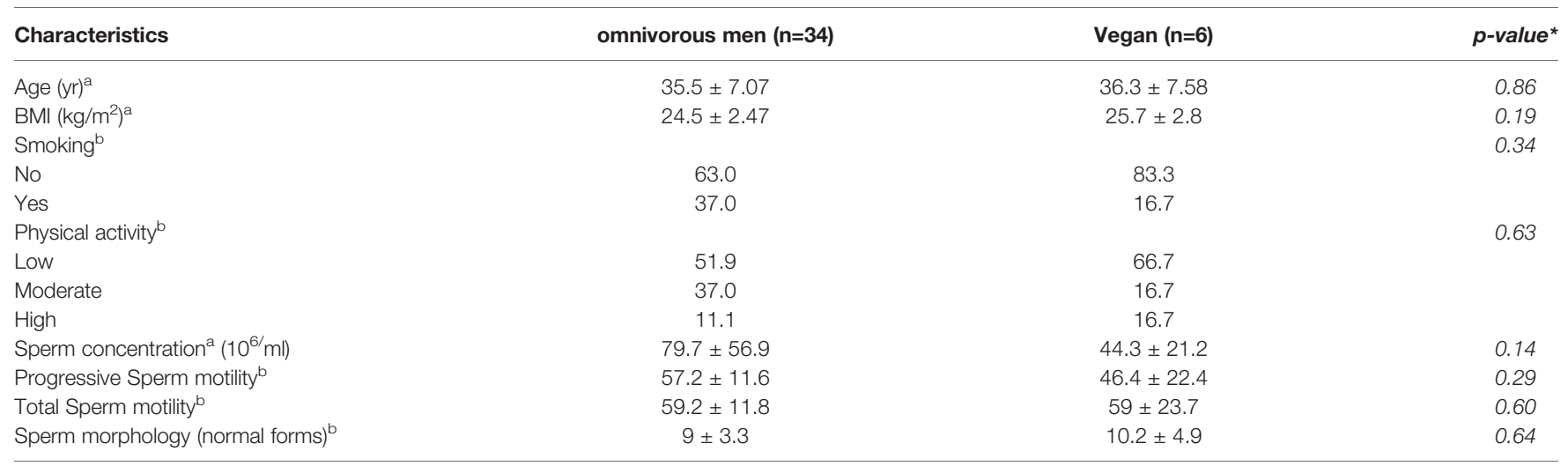

*Mann-Whitney $\cup$ Test or Chi-square test.

${ }^{a}$ Data are presented as means $\pm S D$.

${ }^{b}$ Data are presented as percent (\%). 
TABLE 3 | Methylation profiles in sperm from vegans and omnivore.

\begin{tabular}{lccc}
\hline CpG Sites & omnivorous men (n=34) & Vegan (n=6) & p-value* \\
\hline FTO gene & & & \\
CpG1\% & $1.44 \pm 1.11$ & $2.83 \pm 1.33$ & $\mathbf{0 . 0 2 4}$ \\
CpG2\% & $2.53 \pm 2.11$ & $7.0 \pm 2.28$ & $\mathbf{0 . 0 0 1}$ \\
CpG3\% & $3.65 \pm 2.45$ & $7.83 \pm 4.75$ & $\mathbf{0 . 0 0 4}$ \\
CpG4\% & $0.85 \pm 1.02$ & $2.33 \pm 0.82$ & $\mathbf{0 . 0 0 3}$ \\
Mean all CpG sites \% & $2.06 \pm 1.48$ & $5.0 \pm 2.19$ & $\mathbf{0 . 0 0 1}$ \\
& & & \\
MC4R gene & & & \\
CPG1\% & $4.12 \pm 1.53$ & $4.17 \pm 1.17$ & 0.80 \\
CpG2\% & $7.0 \pm 2.26$ & $10.17 \pm 3.31$ & $\mathbf{0 . 0 1 6}$ \\
Mean all CpG sites \% & $5.65 \pm 1.76$ & $7.0 \pm 2.28$ & 0.17 \\
H19 gene & & & \\
CpG1\% & $91.5 \pm 2.63$ & $90.5 \pm 1.38$ & 0.23 \\
CpG2\% & $94.41 \pm 2.66$ & $96.33 \pm 3.14$ & 0.17 \\
CpG3\% & $92.26 \pm 2.38$ & $95.17 \pm 1.60$ & $\mathbf{0 . 0 0 7}$ \\
CpG4\% & $92.38 \pm 3.95$ & $95.33 \pm 4.08$ & 0.11 \\
CpG5\% & $98.32 \pm 2.52$ & $100 \pm 0$ & 0.05 \\
Mean all CpG sites \% & $93.74 \pm 2.06$ & $95.33 \pm 1.86$ & 0.12 \\
\hline
\end{tabular}

*Mann-Whitney $\cup$ Test.

Data are presented as means $\pm S D$.

Statistically significant values are in bold.

No significant association was found for FTO genotype neither with BMI (Supplementary Table 1) nor with DNA methylation levels at FTO gene (Supplementary Table 2).

\section{DISCUSSION}

The epigenetics of human sperm currently represents a very promising field of investigation in relation to the growing evidence of the role played by epigenetic alterations in male infertility. Very recently, the presence of sperm epigenomic alterations has been used as a biomarker of the success rate of ART protocols, since patients with specific pattern of sperm DNA methylation are characterized by a poor outcome of these protocols (40). Given the reversible nature of epigenetic modifications, males with aberrant sperm DNA methylation can be considered as excellent candidates to investigate treatments aimed to induce a reversibility of epigenetic alterations. It has been suggested that personalized nutrition could prevent or reverse the detrimental epigenetic modifications induced by unhealthy lifestyles. Since the spermatogenesis process is completed in a few weeks, it could be suggested that a few months period of personal lifestyle care could restore a physiological epigenetic mark of the sperm $(10,41)$. In this view, a crucial point is represented by the knowledge of the specific effect of different diets on the epigenetic pattern of human sperm.

Despite the exact relationship between diet and the epigenome remains unclear, several studies reported an association between epigenetic modifications and dietary depletion or supplementation $(1,42-48)$.

Recent study suggests substantial differences in methylation of $\mathrm{CpG}$ sites and genes, particularly in regulatory regions, between vegans and non-vegetarians, laying the foundation for the identification of transcriptional alterations associated with diet-influenced methylation patterns (49). In addition, genome- wide methylation analysis in the DNA of blood cells showed epigenetic differences in methylation in vegans versus pescatarians and in vegans versus nonvegetarians. In particular, the authors found that vegans had a higher methylation in the majority of the differentially methylated sites, with DNA hypomethylation occurring in only $4 \%$ of all DM probes in the nonvegetarian comparison; this value was $33 \%$ for the pescatarian comparison (50).

Moreover, it has been demonstrated that the sperm epigenome may be responsive to dietary factors $(41,51)$. In this view, we investigated for the first time, to the best of our knowledge, DNA methylation profiles of metabolism-related genes and their associations with vegan diet in sperm of healthy subjects. Our results showed that a vegan diet was associated with higher sperm DNA methylation at the FTO and MC4R genes.

These findings seem to confirm that a specific diet can induce epigenetic modifications in human sperm. The mechanism underlying this process and the possible consequences must be analyzed in detail. A possible explanation is that hypermethylation of FTO and MC4R genes is the result of the increased number of dietary methyl donors available in vegan diet. In fact, nutrients include molecules that constitute DNA and histone methylation, such as methylfolate, choline, betaine, methionine, vitamins B12, B6, and B2 (52). Several studies showed the critical nutrients occurrence for each dietary regime (53-56). In particular, on the micronutrient level, one study carried out on the largest sample of vegan dieters worldwide reported that the men following a vegan diet have lower intake of saturated fatty acids (SFA), retinol, vitamin B12 and $\mathrm{D}$, calcium, zinc than omnivorous diet. On the other hand, higher levels of magnesium, iron, folic acid, vitamin B1, C, and a higher intake of dietary fiber have been shown in vegan compared to omnivore dieters (57). The risk of nutrient deficiencies for specific micronutrients is the major criticism of plant-based diets. In fact, $4 \%$ of vegans are more likely to need supplements and food fortified compared to omnivores (13). Noteworthy, in the present study the vegans reported no kind of dietary supplement. Our findings suggest that the possible imbalances in the metabolism of the methyl nutrients such as vitamins (folate, riboflavin, vitamin B6, choline) and amino acids (methionine, cysteine, serine, glycine) could potentially modulate hypo- or hyper- methylation of DNA. An interesting point is the comparison between our results and those reported in the literature on obese subjects. In fact, it has been described that FTO and MC4R genes show different levels on DNA methylation in obese as compared to lean subjects (41). However, these authors analyzed different CpG islands in these genes and results of the different islands were not consistent. Nevertheless, these results confirm that FTO and MC4R methylation in human sperm can be affected by individual lifestyle. In our study, surprisingly, the vegans had a higher BMI than omnivores, although not statistically significant. This is in contrast with previous studies reporting lower BMI as compared to omnivores whose diet included more proteins and less fibres $(58,59)$. 
Given the potential role of genotype of FTO on gene expression $(6,60)$, we analyzed the effect of genotypes on methylation levels. No significant association was found between genetic variant and DNA methylation levels at FTO gene. To note, rs9939609 was not evaluated in the studies of Doaei et al. $(60,61)$, which pointed to another FTO SNP.

This study has some limitations. First of all, the crosssectional study design. Secondly, the main limit of the study is the small sample size. In the last years, the number of subjects who began to adopt a vegan dietary pattern has increased, but still limited to a minority. To confirm these data, an increase in the number of subjects enrolled and the representation of different dietary groups are needed. The literature on the effects of diet on epigenetic alterations in sperm is limited as studies in this field are hardly available, largely due to difficulties implied by the collection of samples. The possible role of a diet in improving the quality of human sperm is underexplored in the context of sperm epigenetic modifications. As matter of fact, the connection between a vegan diet and sperm DNA methylation patterns in human is widely unknown and needs further insight.

Thirdly, the assessment of diet was occurred by self-report. Fourthly, the examined genes do not play a role in sperm development and function.

A strength of this study is that, to our knowledge, this is the first attempt to evaluate the effects of vegan diet on DNA methylation level at genes involved in metabolism in sperm.

Interestingly, Soubry introduced the Paternal Origins of Health and Disease (POHaD) paradigm emphasizing the paternal transgenerational epigenetic inheritance of metabolic disorders (62). Therefore, the epigenetic modifications of spermatozoa can be transmitted to the offspring and subsequent generations, thus influencing their lifetime health. In this regard, it has been demonstrated that obesity is a factor able to induce reversible sperm epigenetic modifications (8), providing insight into a possible role of specific diets in improving the human sperm quality. In accordance with these observations, we suggest that genes related to metabolism could be susceptible to germ cell epigenetic modulation in response to nutritional status and diet. A greater understanding of epigenetic

\section{REFERENCES}

1. Ideraabdullah FY, Zeisel SH. Dietary Modulation of the Epigenome. Physiol Rev (2018) 98(2):667-95. doi: 10.1152/physrev.00010.2017

2. Parrillo L, Spinelli R, Nicolò A, Longo M, Mirra P, Raciti GA, et al. Nutritional Factors, DNA Methylation,and Risk of Type 2 Diabetes and Obesity: Perspectives and Challenges. Int J Mol Sci (2019) 20(12):2983. doi: 10.3390/ ijms20122983

3. Franzago M, Fraticelli F, Stuppia L, Vitacolonna E. Nutrigenetics, epigenetics and gestational diabetes: consequences in mother and child. Epigenetics (2019) 14(3):215-35. doi: 10.1080/15592294.2019.1582277

4. Franzago M, Santurbano D, Vitacolonna E. Stuppia L.Genes and Diet in the Prevention of Chronic Diseases in Future Generations. Int J Mol Sci (2020) 21 (7):2633. doi: 10.3390/ijms21072633

5. Stuppia L, Franzago M, Ballerini P, Gatta V, Antonucci I. Epigenetics and male reproduction: the consequences of paternal lifestyle on fertility, embryo development, and children lifetime health. Clin Epigenet (2015) 7:120. doi: 10.1186/s13148-015-0155-4 pattern as modifiable component in the periconceptional period may provide new findings and propose a novel conceptualization of susceptibility to metabolic disturbances. This domain of research is solid, but the knowledge of the underlying mechanism is currently still lacking.

\section{DATA AVAILABILITY STATEMENT}

The data underlying this article will be shared on reasonable request to the corresponding author.

\section{ETHICS STATEMENT}

The studies involving human participants were reviewed and approved by Ethics Committee of the University of Padua, Italy protocol number \#2208. The patients/participants provided their written informed consent to participate in this study.

\section{AUTHOR CONTRIBUTIONS}

The study was designed by CF and LS. CF, IS, PP, AL, and MS contributed to clinical evaluation and support to the recruitment of patients. IS, SF, and MF conducted the experiments. MF, IS, and LS contributed to data acquisition. MF, LS, and EV contributed to interpretation of results. MF performed the statistical analysis. The manuscript was drafted by MF and LS. All authors contributed to the article and approved the submitted version. LS and CF are the guarantors of this work.

\section{SUPPLEMENTARY MATERIAL}

The Supplementary Material for this article can be found online at: https://www.frontiersin.org/articles/10.3389/fendo.2021.633943/ full\#supplementary-material

6. Denham J, O'Brien BJ, Harvey JT, Charchar FJ. Genome-wide sperm DNA methylation changes after 3 months of exercise training in humans. Epigenomics (2015) 7(5):717-31. doi: 10.2217/epi.15.29

7. Soubry A, Guo L, Huang Z, Hoyo C, Romanus S, Price T, et al. Obesityrelated DNA methylation at imprinted genes in human sperm: Results from the TIEGER study. Clin Epigenet (2016) 8:51. doi: 10.1186/s13148-0160217-2

8. Donkin I, Versteyhe S, Ingerslev LR, Qian K, Mechta M, Nordkap L, et al. Obesity and bariatric surgery drive epigenetic variation of spermatozoa in humans. Cell Metab (2016) 23(2):369-78. doi: 10.1016/j.cmet.2015.11.004

9. Ingerslev LR, Donkin I, Fabre O, Versteyhe S, Mechta M, Pattamaprapanont $\mathrm{P}$, et al. Endurance training remodels sperm-borne small RNA expression and methylation at neurological gene hotspots. Clin Epigenet (2018) 25(10):12. doi: 10.1186/s13148-018-0446-7

10. de Castro Barbosa T, Ingerslev LR, Alm PS, Versteyhe S, Massart J, Rasmussen $M$, et al. High fat diet reprograms the epigenome of rat spermatozoa and transgenerationally affects metabolism of the offspring. Mol Metab (2015) 5 (3):184-97. doi: 10.1016/j.molmet.2015.12.002 
11. Franzago M, Rovere M, Franchi PG, Vitacolonna E, Stuppia L. Epigenetics and human reproduction: the primary prevention of the noncommunicable diseases. Epigenomics (2019) 11(12):1441-60. doi: 10.2217/epi-2019-0163

12. Dinu M, Abbate R, Gensini GF, Casini A, Sofi F. Vegetarian, vegan diets and multiple health outcomes: A systematic review with meta-analysis of observational studies. Crit Rev Food Sci Nutr (2017) 57(17):3640-9. doi: 10.1080/10408398.2016.1138447

13. Allès B, Baudry J, Méjean C, Touvier M, Péneau S, Hercberg S, et al. Comparison of sociodemographic and nutritional characteristics between self-reported vegetarians, vegans, and meat-eaters from the Nutrinet-Sante study. Nutrients (2017) 9(9):1023. doi: 10.3390/nu9091023

14. Craig WJ. Health effects of vegan diets. Am J Clin Nutr (2009) 89:1627S-33S. doi: 10.3945 /ajcn.2009.26736N

15. Le LT, Sabate J. Beyond meatless, the health effects of vegan diets: Findings from the Adventist cohorts. Nutrients (2014) 6:2131-47. doi: 10.3390/ nu6062131

16. Medawar E, Huhn S, Villringer A, Veronica Witte A. The effects of plantbased diets on the body and the brain: a systematic review. Transl Psychiatry (2019) 9(1):226. doi: 10.1038/s41398-019-0552-0

17. Cetin I, Bühling K, Demir C, Kortam A, Prescott SL, Yamashiro Y, et al. Impact of Micronutrient Status during Pregnancy on Early Nutrition Programming. Ann Nutr Metab (2019) 74(4):269-78. doi: 10.1159/000499698

18. Gholamalizadeh M, Jarrahi AM, Akbari ME, Rezaei S, Doaei S, Mokhtari Z, et al. The possible mechanisms of the effects of IRX3 gene on body weight: an overview. Arch Med Sci Atheroscler Dis (2019) 4:e225-30. doi: 10.5114/ amsad.2019.87545

19. Hinney A, Volckmar A-L, Knoll N. Melanocortin-4 receptor in energy homeostasis and obesity pathogenesis. In:Prog Mol Biol Transl Sci (2013) 114:147-91. doi: 10.1016/B978-0-12-386933-3.00005-4

20. Dina C, Meyre D, Gallina S, Durand E, Körner A, Jacobson P, et al. Variation in FTO contributes to childhood obesity and severe adult obesity. Nat Genet (2007) 39(6):724-6. doi: 10.1038/ng2048

21. Fredriksson R, Hagglund M, Olszewski PK, Stephansson O, Jacobsson JA, Olszewska AM, et al. The obesity gene, FTO, is of ancient origin, up-regulated during food deprivation and expressed in neurons of feeding-related nuclei of the brain. Endocrinology (2008) 149(5):2062-71. doi: 10.1210/en.2007-1457

22. Cecil JE, Tavendale R, Watt P, Hetherington MM, Palmer CN. An obesityassociated FTO gene variant and increased energy intake in children. $N$ Engl J Med (2008) 359(24):2558-66. doi: 10.1056/NEJMoa0803839

23. Peng S, Zhu Y, Xu F, Ren X, Li X, Lai M. FTO gene polymorphisms and obesity risk: a meta-analysis. BMC Med (2011) 8(9):71. doi: 10.1186/17417015-9-71

24. Loos RJ. Genetic determinants of adiposity. In: ME Symonds, editor. Adipose Tissue Biology. New York: Springer Science (2012). p. 317-3.

25. Brunkwall L, Ericson U, Hellstrand S, Gullberg B, Orho-Melander M, Sonestedt E. Genetic variation in the fat mass and obesity-associated gene (FTO) in association with food preferences in healthy adults. Food Nutr Res (2013) 12:57. doi: 10.3402/fnr.v57i0.20028

26. Qi Q, Downer MK, Kilpeläinen TO, Taal HR, Barton SJ, Ntalla I, et al. Dietary intake, FTO genetic variants and adiposity: a combined analysis of over 16,000 children and adolescents. Diabetes (2015) 64:2467-76. doi: 10.2337/db141629

27. Frayling TM, Timpson NJ, Weedon MN, Zeggini E, Freathy RM, Lindgren $\mathrm{CM}$, et al. A common variant in the FTO gene is associated with body mass index and predisposes to childhood and adult obesity. Science (2007) 316:88994. doi: 10.1126/science.1141634

28. Stutzmann F, Cauchi S, Durand E, Calvacanti-Proença C, Pigeyre M, Hartikainen AL, et al. Common genetic variation near MC4R is associated with eating behaviour patterns in European populations. Int J Obes (Lond) (2009) 33:373-8. doi: 10.1038/ijo.2008.279

29. Bauer F, Elbers CC, Adan RA, Loos RJ, Onland-Moret NC, Grobbee DE, et al. Obesity genes identified in genome-wide association studies are associated with adiposity measures and potentially with nutrient-specific food preference. Am J Clin Nutr (2009) 90:951-9. doi: 10.3945/ajcn.2009.27781

30. Hardy R. Life course variations in the associations between FTO and MC4R gene variants and body size. Hum Mol Genet (2009) 120:2345-59. doi: $10.1093 / \mathrm{hmg} / \mathrm{ddp} 504$
31. Church C, Moir L, McMurray F, Girard C, Banks GT, Teboul L, et al. Overexpression of Fto leads to increased food intake and results in obesity. Nat Genet (2010) 42:1086-92. doi: 10.1038/ng.713

32. Ahmad T, Chasman DI, Mora S, Paré G, Cook NR, Buring JE, et al. The fatmass and obesity-associated (FTO) gene, physical activity, and risk of incident cardiovascular events in white women. Am Heart J (2010) 160:1163-9. doi: 10.1016/j.ahj.2010.08.002

33. Cecil J, Dalton M, Finlayson G, Blundell J, Hetherington M, Palmer C. Obesity and eating behaviour in children and adolescents: contribution of common gene polymorphisms. Int Rev Psychiatry (2012) 24:200-10. doi: 10.3109/ 09540261.2012 .685056

34. Castellini G, Franzago M, Bagnoli S, Lelli L, Balsamo M, Mancini M, et al. Fat mass and obesity-associated gene (FTO) is associated to eating disorders susceptibility and moderates the expression of psychopathological traits. PloS One (2017) 12(3):10. doi: 10.1371/journal.pone.0173560

35. Fairbrother U, Kidd E, Malagamuwa T, Walley A. Genetics of Severe Obesity. Curr Diabetes Rep (2018) 18(10):85. doi: 10.1007/s11892-018-1053-x

36. Franzago M, Fraticelli F, Marchetti D, Celentano C, Liberati M, Stuppia L, et al. Nutrigenetic variants and cardio-metabolic risk in women with or without gestational diabetes. Diabetes Res Clin Pract (2018) 137:64-71. doi: 10.1016/j.diabres.2018.01.001

37. Crovesy L, Rosado EL. Interaction between genes involved in energy intake regulation and diet in obesity. Nutrition (2019) 67-68:110547. doi: 10.1016/ j.nut.2019.06.027

38. WHO. World Health Organization laboratory manual for the examination and processing of human semen. 5th ed. Geneva: WHO Press (2010).

39. Mendoza-Pérez J, Gu J, Herrera LA, Tannir NM, Zhang S, Matin S, et al. Prognostic significance of promoter CpG island methylation of obesity-related genes in patients with nonmetastatic renal cell carcinoma. Cancer (2017) 123 (18):3617-27. doi: 10.1002/cncr.30707

40. Jenkins TG, Aston KI, James ER, Carrell DT. Sperm epigenetics in the study of male fertility, offspring health, and potential clinical applications. Syst Biol Reprod Med (2017) 63(2):69-76. doi: 10.1080/19396368.2016.1274791

41. Donkin I, Barrès R. Sperm epigenetics and influence of environmental factors. Mol Metab (2018) 14:1-11. doi: 10.1016/j.molmet.2018.02.006

42. Hoek J, Steegers-Theunissen RP, Willemsen SP, Schoenmakers S. Paternal Folate Status and Sperm Quality, Pregnancy Outcomes, and Epigenetics: A Systematic Review and Meta-Analysis. Mol Nutr Food Res (2020) 64 (9):1900696. doi: 10.1002/mnfr.201900696

43. Curtis EM, Krstic N, Cook E, D’angelo S, Crozier SR, Moon RJ, et al. Gestational vitamin D supplementation leads to reduced perinatal RXRA DNA methylation: results from the MAVIDOS trial. J Bone Miner Res (2019) 34(2):231-40. doi: 10.1002/jbmr.3603

44. Nur SM, Rath S, Ahmad V, Ahmad A, Ateeq B, Khan MI. Nutritive vitamins as epidrugs. Crit Rev Food Sci Nutr (2021) 61(1):1-13. doi: 10.1080/ 10408398.2020.1712674

45. Ong LT, Booth DR, Parnell GP. Vitamin D and its Effects on DNA Methylation in Development, Aging, and Disease. Mol Nutr Food Res (2020) 64(23):2000437. doi: 10.1002/mnfr.202000437

46. Keleher MR, Zaidi R, Hicks L, Shah S, Xing X, Li D, et al. A high-fat diet alters genome-wide DNA methylation and gene expression in SM/J mice. BMC Genom (2018) 19:888. doi: 10.1186/s12864-018-5327-0

47. Keleher MR, Zaidi R, Shah S, Oakley ME, Pavlatos C, El Idrissi S, et al. Maternal high-fat diet associated with altered gene expression, DNA methylation, and obesity risk in mouse offspring. PloS One (2018) 13: e0192606. doi: 10.1371/journal.pone.0192606

48. ElGendy K, Malcomson FC, Lara JG, Bradburn DM, Mathers JC. Effects of dietary interventions on DNA methylation in adult humans: Systematic review and meta-analysis. Br J Nutr (2018) 120:961-76. doi: 10.1017/ S000711451800243X

49. Miles FL, Mashchak A, Filippov V, Orlich MJ, Duerksen-Hughes P, Chen X, et al. DNA Methylation Profiles of Vegans and Non-Vegetarians in the Adventist Health Study-2 Cohort. Nutrients (2020) 12(12):3697. doi: 10.3390/nu12123697

50. Filippov V, Jaceldo-Siegl K, Eroshkin A, Loskutov V, Chen X, Wang C, et al. Methylomes in Vegans versus Pescatarians and Nonvegetarians. Epigenomes (2020) 4:28. doi: 10.3390/epigenomes 4040028 
51. Bodden C, Hannan AJ. Reichelt AC Diet-Induced Modification of the Sperm Epigenome Programs Metabolism and Behavior. Trends Endocrinol Metab (2020) 31(2):131-49. doi: 10.1016/j.tem.2019.10.005

52. Obeid R. The metabolic burden of methyl donor deficiency with focus on the betaine homocysteine methyltransferase pathway. Nutrients (2013) 5 (9):3481-95. doi: 10.3390/nu5093481

53. Clarys P, Deliens T, Huybrechts I, Deriemaeker P, Vanaelst B, De Keyzer W, et al. Comparison of nutritional quality of the vegan, vegetarian, semivegetarian, pesco-vegetarian and omnivorous diet. Nutrients (2014) 6:131832. doi: $10.3390 /$ nu6031318

54. Schüpbach R, Wegmüller R, Berguerand C, Bui M, Herter-Aeberli I. Micronutrient status and intake in omnivores, vegetarians and vegans in Switzerland. Eur J Nutr (2017) 56:283-93. doi: 10.1007/s00394-015-1079-7

55. Weikert C, Trefflich I, Menzel J, Obeid R, Longree A, Dierkes J, et al. Vitamin and Mineral Status in a Vegan Diet. Deutsches Aerzteblatt Int (2020) 117(3536):575-82. doi: 10.3238/arztebl.2020.0575

56. Bakaloudi DR, Halloran A, Rippin HL, Oikonomidou AC, Dardavesis TI, Williams J, et al. Intake and adequacy of the vegan diet. A systematic review of the evidence. Clin Nutr (2020) 2020:S0261-5614(20)30656-7. doi: 10.3238/ arztebl.2020.0575

57. Davey GK, Spencer EA, Appleby PN, Allen NE, Knox KH, Key TJ. EPICOxford: lifestyle characteristics and nutrient intakes in a cohort of 33883 meat-eaters and 31546 non meat-eaters in the UK. Public Health Nutr (2003) 6:259-68. doi: 10.1079/PHN2002430

58. Spencer EA, Appleby PN, Davey GK, Key TJ. Diet and body mass index in 38000 EPIC-Oxford meat-eaters, fish-eaters, vegetarians and vegans. Int J Obes Relat Metab Disord (2003) 27(6):728-34. doi: 10.1038/sj.ijo.0802300
59. Tonstad S, Butler T, Yan R, Fraser GE. Type of vegetarian diet, body weight, and prevalence of type 2 diabetes. Diabetes Care (2009) 32(5):791-6. doi: $10.2337 / \mathrm{dc} 08-1886$

60. Doaei S, Kalantari N, Izadi P, Salonurmi T, Jarrahi AM, Rafieifar S, et al. Interactions between macro-nutrients' intake, FTO and IRX3 gene expression,and FTO genotype in obese and overweight male adolescents. Adipocyte (2019) 8(1):386-91. doi: 10.1080/21623945. 2019.1693745

61. Doaei S, Kalantari N, Izadi P, Salonurmi T, Mosavi Jarrahi A, Rafieifar S, et al. Changes in FTO and IRX3 gene expression in obese and overweight male adolescents undergoing an intensive lifestyle intervention and the role of FTO genotype in this interaction. J Transl Med (2019) 17(1):176. doi: 10.1186/ s12967-019-1921-4

62. Soubry A. POHaD: why we should study future fathers. Environ Epigenet (2018) 4(2):dvy007. doi: 10.1093/eep/dvy007

Conflict of Interest: The authors declare that the research was conducted in the absence of any commercial or financial relationships that could be construed as a potential conflict of interest.

Copyright (C) 2021 Franzago, Sabovic, Franchi, De Santo, Di Nisio, Luddi, Piomboni, Vitacolonna, Stuppia and Foresta. This is an open-access article distributed under the terms of the Creative Commons Attribution License (CC BY). The use, distribution or reproduction in other forums is permitted, provided the original author(s) and the copyright owner(s) are credited and that the original publication in this journal is cited, in accordance with accepted academic practice. No use, distribution or reproduction is permitted which does not comply with these terms. 